\title{
Examining younger and older adults' digital gaming habits and health measures
}

\author{
Ulla Bunz $\mathrm{PhD}^{\mathrm{a}, *}$, Juliann Cortese $\mathrm{PhD}^{\mathrm{a}}$, Nicholas Sellers $\mathrm{PhD}^{\mathrm{b}}$ \\ ${ }^{a}$ School of Communication, Florida State University, Tallahassee, FL, USA; ${ }^{b}$ Florida State \\ University, Panama City, FL, USA; *Corresponding author: ubunz@fsu.edu
}

\begin{abstract}
Background: Older adults are increasingly playing digital games, not just for therapeutic purposes, but also for personal entertainment. Prior work has shown that such gameplay has a variety of benefits for older adults, including socialization, as well as cognitive, physical, and mental health. Comparing younger and older adults provides a snapshot of gaming and its influence across the lifespan.

Objective: The purpose of this study was to examine younger and older adults' digital gaming habits to understand the similarities and differences in how they participate in gaming activities. Furthermore, this study seeks to examine general health measures for each group and to determine if gaming habits affect general health indicators. Five research questions investigated games played, frequency of play, platform use, influences to begin gaming, and how gaming frequency and genre affect participants' physical and mental health.

Methods: A survey was completed by 295 participants. The questionnaire included the CES-Depression, PANAS, and SF-36 scales, as well as demographic questions, questions about games played, frequency of play, influence to begin playing, and platform use.

Results: Results show that both younger and older adults play puzzle games and use mobile devices, but each age group also has other digital games and platforms it prefers. Older adults are more likely to game every day or at least once a week, which is more frequently than younger adults. Both groups were most likely to begin playing a specific digital game due to interpersonal influences-friends for younger adults and family members for older adults. Older adults showed better mental health. Younger adults had higher scores for physical health, depression, and negative affect. Gaming frequency and game genre affected health measures to a certain degree.

Conclusions: Both marketing and medical professionals can benefit from the results by targeting specific game genres, platforms, and influencers identified. Differences in gaming and its effect on health measures between age groups may be diminishing as more and more gamers mature into older adults.
\end{abstract}

Keywords: Gaming, digital games, age comparison, game genre, older adults

\section{INTRODUCTION}

\section{Background and purpose}

Much research exists on gaming and its effects on health and behavior. The popular press seems to emphasize negative effects, such as addiction and attempts to link playing violent games and real-life violent behavior. Less attention is paid to the positive effects of digital gaming such as the learning and entertainment effects of educational games for the young. Digital gaming can also bring positive health benefits. Allaire et al. (2013) showed that older adults who played digital games did better on measures of well-being, negative affect, social functioning, and depression than older adults who were non-gamers.

Digital gaming (from here on, "gaming") is continuing to be pervasive in society, as a recent Pew study showed (Duggan, 2015). According to this study, $50 \%$ of men and $48 \%$ of women play some type of video game. Young adults (aged 18 to 29$)$, in particular, are game players $(67 \%)$, but older adults are also an important group of players with $40 \%$ aged 50 to 64 playing games, and $25 \%$ of adults older than 65 . As these game players continue to grow older, the percentage of older adults who play games will grow.

The current study was based on the notions that gaming can have positive effects, and that gaming occurs at both younger and older adult ages. The purpose of this study was to examine younger and older adults' digital gaming habits to understand better the similarities and differences in how different adult age groups participate in gaming activities. Furthermore, this study seeks to examine general health measures for each group and to determine if gaming habits affect general health indicators. While only presenting a snapshot of data in time, examining both 
younger and older adults will help clarify whether positive effects may occur across the adult lifespan. In addition, the project determined who caused participants to begin playing digital games. Identifying gaming patterns across the life span and determining the greatest influence to begin gaming is useful information to those developing and implementing health games to improve cognitive function, and physical and mental health for the entire adult population.

\section{Related literature \\ General gaming data with emphasis on older adults}

Existing research on older adult digital gaming often states basic frequencies (e.g., what percent of people aged this to that play games, consider themselves gamers, or have been gaming for a certain period of time). Some studies were identified that investigate the benefits of intergenerational gameplay within families, such as grandparents and grandchildren (e.g. Costa, \& Veloso, 2016; de la Hera, Loos, Simons, \& Blom, 2017), or for longer-term non-family-based intergenerational relationships (e.g. Chua, Jung, Lwin, \& Theng, 2013), such as cross-generational friendships or mentor-mentee relationships. While the general stereotype of a "gamer" as a solitary male teenager playing first-person shooter games has some basis in reality (Duggan, 2015; Lenhart, Jones, \& MacGill, 2008; MacGill, 2007), we know that many adults, including women and older adults, are playing games with increasing frequency (Duggan, 2015). Brown (2017) offered that almost $40 \%$ of women now play video games, as do nearly a quarter of Americans over the age of 65 . What these survey data do not explore is which types of games gamers are playing the most. The study at hand fills this gap.

Some studies examine the motivations of older gamers. Quandt, Grueninger, and Wimmer (2009), conducting qualitative in-depth interviews with older gamers, found that the social aspects of gaming, particularly online, were important to older gamers, with some believing that gaming could provide common ground with younger generations. Many older gamers enjoy the social aspects of online gaming and are playing more games online (De Schutter, 2011). In De Schutter's study, the audience was primarily female and preferred puzzle games. In contrast, Kaufman, Sauvé, Renaud, Sixsmith, and Mortenson (2016) found that only a relatively small percentage of respondents reported enjoying the socio-emotional benefits of gaming. These studies provide a beginning point for data on older gamers. Learning more about older adults' gaming interests would go a long way towards further establishing this group as a consumer group worthy of targeted marketing, and as a group for whom gaming can have health benefits.

Comparisons between younger and older gamers exist but are often limited in scope. For example, Griffiths, Davies, and Chappell (2004) found that both adolescents and adults reported enjoying the social features of online gaming, but adolescents were more likely to report that violence was their favorite aspect. Salmon et al. (2017) examined the differences between younger and older gamers based on preferences for genres, and report that both younger and older gamers rated the same game features as most important and showed preferences for puzzle and strategy games. To assess a baseline for comparison between older and younger adults, three research questions were developed for this study.

RQ1: What types of games do younger versus older adults play most frequently?

RQ2: How does the frequency with which adults play digital games differ between younger and older adults?

RQ3: Does the platform on which adults play digital games most frequently differ between younger and older adults?

Beyond basic information on gameplay, there is evidence that gaming can have positive effects on physical and mental health. However, research studies are not always consistent in their findings in this realm, as some studies show clear negative health effects of gaming. The following briefly presents both sides.

\section{Negative health effects}

There is evidence that gaming can have negative health effects, both physical and mental. Physical negative effects are primarily due to being sedentary rather than active and are often associated with screen time. This effect applies to other technologies as well, such as general computer or Internet use, or television watching (e.g. Norman et al., 2017; Soler-Lanagran \& Castaneda-Vazquez, 2017).

Previous studies of the mental health effects of technology demonstrate a variety of negative outcomes. Nap, Ijsselsteijn, and de Kort (2009) compared young adults and seniors on their perceptions, experiences, and domain knowledge about digital gaming. Confirming to stereotype, seniors' knowledge about digital gaming was more limited than young adults'. Also, seniors had more concerns about the possible negative effects of gaming on those who play. Even without empirical evidence, the perception alone can cause mental health to decline, as concern about negative effects can lead to anxiety. In addition, seniors who are concerned that gaming might have negative effects are less likely to partake in gaming and are thus missing out on 
potential positive effects.

Anderson et al. (2010) found that playing violent games can lead to negative mental health effects, including a decline of prosocial behavior and empathy, as well as an increase in aggressive behavior, cognition, and affect. The authors found that this effect holds across eastern and western cultures, for both short- and long-term contexts, and for both men and women.

In addition to aggression, research shows that gaming can lead to problematic technology use or addiction. For example, LaRose, Lin, and Eastin (2003) found that if depression or addiction is present, media use can exacerbate deficient selfregulation and possibly lead to media addiction. This could include gaming, especially because games are inherently designed to be addictive. As Ferguson, Coulson, and Barnett (2011) discuss, gaming addiction is a serious concern. Referring to "pathological video gaming," the authors concluded that pathological gaming certainly exists, but may be over-identified when pathological gaming was the focus of the investigation. Instead, the authors recommended investigating how gaming interferes with other life activities.

\section{Positive health effects}

Literature also exists that shows that gaming can have positive health effects, both mental and physical. Primack et al. (2012) found 38 studies showing positive health effects as a result of video gameplay. Among other results, the authors concluded that $69 \%$ of psychological therapy outcomes and 59\% of physical therapy outcomes improved with the use of video games.

Bleakley et al. (2015) report that games are used to improve aerobic health, strength, balance, and flexibility, and gameplay can result not just in physical health improvements, but also in enjoyment, including in older adults. The use of virtual reality technology can lead to an increase in functional balance and dual-task reaction times in older adults (Bisson, Contant, Sveistrup, \& Lajoie, 2007), and in an improvement of motor control amongst older adults (de Bruin, Schoene, Pichierri, \& Smith, 2010). Fent, Little, Garver, Murray, and Todd (2015) found similarly positive effects for senior adults' balance, fitness, and mood as a result of playing Wii Fit ${ }^{\mathrm{TM}}$.

Other studies show clear positive health effects on mental health. Jones, Scholes, Johnson, Katsikitis, and Carras (2014) focused on people's overall well-being and "flourishing", defined as "a combination of feeling good and functioning effectively resulting in high levels of mental well-

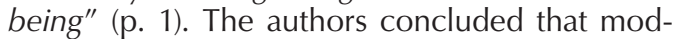
erate amounts of gameplay (of certain types of games) can "lead to improved mood, reduced emotional disturbance, improve emotion regulation, relaxation, and stress reduction" (p. 7).

Such conclusions support Allaire et al.'s (2013) research referenced earlier where gaming participants showed a better well-being, social functioning, and lower depression and negative affect than non-gamers. In fact, for adult gamers, Eklund (2015) found that online gaming is often related to offline social ties. By playing the same game, even separate from each other, people would be able to share digital gaming experiences with offline friends, strengthening these relational ties.

As the brief review of health and gaming literature above shows, while the potential for negative gaming effects exists, positive effects are also clearly documented. Thus, finding out who influences adults' game-playing would allow targeted health campaigns outside of the doctor-patient context.

RQ4: How do the influences to begin playing digital games differ between younger and older adults?

In addition, regarding positive and negative health effects and their relationship to gaming and potential differences between age groups, research questions 5a, 5b, and 5c were developed. Research question 5 a serves as a foundation for the other two questions as one should first investigate whether there even is a difference in a base measure before looking at possible confounding factors.

RQ5a: How do younger and older adults' health measures (depression, positive and negative affect, physical health, and mental health) differ? RQ5b: Considering their digital gaming frequency, how do younger and older adults' health measures (depression, positive and negative affect, physical health, and mental health) differ? RQ5c: Considering their most played game's genre, how do younger and older adults' health measures (depression, positive and negative affect, physical health, and mental health) differ?

\section{Methods \\ Survey instrument}

An 86-item questionnaire was constructed containing sections on health, gaming, and demographics. The health section consisted of the 36-item Medical Outcomes Study SF-36 scale assessing general health, physical health, and emotional health (Ware \& Gandek, 1998); the 20-item Center for Epidemiological Studies (CES) Depression scale (Radloff, 1977); and the 20-item Positive and Negative Affect Schedule (PANAS; Watson, Clark, \& Tellegen, 1988). These scales have been vetted over time and consistently report Cronbach's reliability alphas above .70. 
Table 1. Scales and sub-scales drawn from the literature (Cronbach's alpha).

\begin{tabular}{lc}
\hline Scale & Alpha \\
\hline CES Depression scale & .744 \\
Depressed Affect subscale & .877 \\
Interpersonal subscale & .701 \\
Other Affect subscale & .720 \\
Positive Affect subscale & .879 \\
Somatic and Retarded Activity subscale & .714 \\
\hline Positive Affect and Negative Affect scale & .729 \\
Negative Affect subscale & .870 \\
Positive Affect subscale & .896 \\
\hline SF 36-Mental Health scale & .919 \\
\hline SF 36- Physical Health scale & .938 \\
Bodily Pain subscale & .855 \\
General Health subscale & .831 \\
Mental Health subscale & .870 \\
Physical Functioning subscale & .949 \\
Role-Emotional subscale & .810 \\
Role-Physical subscale & .894 \\
Social Functioning subscale & .790 \\
Vitality subscale & .829 \\
\hline
\end{tabular}

There were three demographic questions, age, gender, and race/ethnicity, as well as two questions on gaming platform (based on Peng \& Zhu, 2011) asking which of the following technologies were used "most" (check one answer) or "regularly" (check all that apply) for digital gaming. For both questions, technology platforms listed included the "desktop computer, laptop computer, tablet, mobile phone, and TV with console (e.g. Wii)".

The gaming section also included a question on gaming frequency that asked, "How often do you play digital games?" with a 5-point answer option ranging from "1-Less than once a month" to "5-every day". We also added a sixth option, "I do not currently play any digital games." to filter out participants who missed this stipulation in the consent form. Similar measures have been used by previous researchers (e.g., De Schutter, 2011).

Finally, we added a question that asked participants to list the digital games they played most frequently, second most frequently, and third most frequently within the past four weeks. For each of these games, we then asked respondents to identify who or what had influenced them the most to play this game (e.g. friend, family, ad, commercial, etc.).

\section{Data collection procedure}

Data generated by the younger adults were collected by recruiting students enrolled in courses at a large, public university in the southeast of the United States. These courses draw students from across the university. Students were offered course credit for participation.

To reach out to older adults specifically, we worked with our university's Institute for Successful Longevity. The Institute keeps a database of people who have indicated an interest in participating in research studies. Nineteen usable questionnaires were completed. We also recruited an additional 27 older participants, who were paid \$6 for their participation, via Amazon's Mechanical Turk service. All participants agreed to an informed consent document prior to completing the questionnaire (Florida State University, approval number 2017.20655).

\section{ResUlts}

A total of 295 usable surveys were completed. The participants fell into two age groups, with the "younger adults" group (18-29) containing 249 subjects with a mean age of 20.21 (SD $=1.72$ ). Ad hoc, we defined the "older adults" group as anyone 50 or older, based on the AARP definition (About AARP, n.d.). The sample contained 46 participants with a mean age of 65.8 years $(S D=6.15$, range 56-79).

Samples with unequal sizes should be weighted based on an auxiliary variable, such as the distribution of the variable in the actual population (Bethlehem, 2009). Thus, census data for 2016 was retrieved for the applicable age groups. To these, we applied the proportion of game players based on a Pew article (Duggan, 2015). The resulting weights were applied throughout the analysis whenever age groups were compared. SPSS version 25 was used for the analyses. Where effect-size values were not available directly from SPSS, G*Power 3.1.9.4 was used for calculation. All scales and sub-scales drawn from the literature achieved reliability scores between .701 and .949 (Cronbach's alpha; see Table 1 for specific alphas).

\section{RQ1: What types of games do younger versus older adults play most frequently?}

There was some variety in the games participants play. We asked all participants to identify the three games they play most frequently (ranked). After grouping different versions of the same game (e.g. FreeCell and Spider Solitaire were both grouped into "Solitaire"), games were further classified into a game genre (e.g. card game, shooter game, etc.) by two coders.

Overall, comparing younger and older adults' game genre choices, both groups liked playing puzzle games (Table 2 for all rankings). Their other top choices varied by age group with younger adults choosing more activity-oriented games (sports, shooting), while older adults preferred more cognitive-oriented games (card, board, simulation).

\section{RQ2: How does the frequency with which adults play digital games differ between younger and older adults?}

The frequency with which adults play digital games differs significantly between younger and 
Table 2. Gaming genre frequency.

\begin{tabular}{lcc}
\hline & Younger sample & Older sample \\
\hline Most played & Puzzle $(21.5 \%)$ & Puzzle $(29 \%)$ \\
& Sports $(19 \%)$ & Card $(18.1 \%)$ \\
Second most & First-person shooter $(14.8 \%)$ & Board $(7.7 \%)$ \\
& Sports $(22.1 \%)$ & Puzzle $(47.2 \%)$ \\
Third most & Puzzle $(16.9 \%)$ & Card $(31.6 \%)$ \\
& First-person shooter $(14 \%)$ & First-person shooter $(9.1 \%)$ \\
& First-person shooter $(17 \%)$ & Puzzle $(34.4 \%)$ \\
& Puzzle $(12.3 \%)$ & Card $(32.1 \%)$ \\
\hline
\end{tabular}

older adults, $\mathrm{t}(215)=-7.03, \mathrm{p}<.001, \mathrm{~d}=.96$. Older adults were more likely to play "every day" (55\%) than younger adults (12\%). Only $59 \%$ of younger adults indicated that they play digital games once a week or more frequently, while $85.7 \%$ of older adults indicated this.

RQ3: Does the platform on which adults play digital games most frequently differ between younger and older adults?

Crosstab analyses were used to answer this research question. Each crosstab compared age (younger/older sample) by whether or not the indicated platform was chosen for "regularly used" and for "most used".

\section{Regularly used}

Significant associations emerged for all comparisons but one, the comparison of age groups in their use of laptops for gaming (Table 3). The indicating that older adults were more likely to use desktops (4.02 times more likely, $X^{2}(1)=11.02$, $\mathrm{p}=.001$, Cramer's $\mathrm{V}=.226)$ and tablets (7.58 times more likely, $X^{2}(1)=32.40, p<.001$, Cramer's V=.387) for gaming than younger adults. Also, younger adults were more likely to use mobile phones (1.78 times more likely, $X^{2}(1)=4.23, p=.04$, Cramer's $V=.140)$ and TV consoles (7.30 times more likely, $X^{2}(1)=33.71, p<.001$, Cramer's V=.394) for gaming than older adults. Still, many older adults used mobile phones regularly for gaming (45.7\%).

\section{Used most}

All comparisons resulted in significant findings for the "used most" analyses (Table 4). Older adults were significantly more likely than younger adults to indicate that the platforms they used most were desktops (5.04 times more likely, $X^{2}(1)=11.21, \quad p=.001$, Cramer's $V=.227$ ), laptops (2.42 times more likely, $X^{2}(1)=7.44, p=.006$, Cramer's $V=.185)$, and tablets (36.69 times more likely, $X^{2}(1)=28.40, p<.001$, Cramer's V=.363). On the other hand, younger adults were more likely

\section{adults?} other analyses resulted in significant associations

than older adults to report that they used mobile phones $(2.51$ times more likely, $X^{2}(1)=9.285$, $\mathrm{p}=.002$, Cramer's V $=.207)$ and TV consoles (14.71 times more likely, $X^{2}(1)=36.07, \quad p<.001, \quad$ Cramer's $\mathrm{V}=.407$ ) most for gameplay.

\section{RQ4: How do the influences to begin playing digital games dif- fer between younger and older}

Frequency analysis showed that there were differences in who or what influenced younger versus older adults to start playing the three games they had played most frequently within the past four weeks, with friends and family members emerging as influencers for both (Table 5).

A direct comparison via Pearson chi-square analysis showed that younger participants were 3.8 times more likely than older participants to identify friends who were already playing the game as an influence for choosing the game they played most frequently in the past four weeks, $X^{2}(1)=20.59, p<.001$, Cramer's V=.309, and also for the game played second most frequently, $\mathrm{X}^{2}(1)=22.83, \mathrm{p}<.001$ Cramer's $\mathrm{V}=.325$. Younger participants were 2.8 times more likely than older adults to identify friends as an influence to begin playing for their third most played game, $\mathrm{X}^{2}(1)=12.76, \mathrm{p}<.001$ Cramer's V $=.243$.

Older participants were 2.88 times more likely to identify a family member who was already playing the game as an influence to begin playing their second most frequently played game, $X^{2}(1)=6.33, p<.05$ Cramer's $V=.197$. There was no significant chi-square result regarding family for the most frequently played game, or the third most frequently played game.

RQ5a: How do younger and older adults' health measures (depression, positive and negative affect, physical health, and mental health) differ? To assess the differences in younger versus older adults' health, a series of t-tests were conducted on the weighted sample. Ten of the eleven analyses were significant (Table 6), indicating that younger participants exhibited higher depression, more negative affect, and better physical health than the older participants and that older participants had better mental health and more positive affect than younger participants. Variances of the two age groups could not be considered equal for those comparisons based on

Table 3. Platforms used regularly for gaming.

\begin{tabular}{lccccc}
\hline & Desktop & Laptop & Tablet & Mobile phone & TV console \\
\hline Younger adults & $6.7 \%$ & $37.2 \%$ & $5.5 \%$ & $66.4 \%$ & $47.4 \%$ \\
Older adults & $19.6 \%$ & $47.8 \%$ & $46.5 \%$ & $45.7 \%$ & $6.5 \%$ \\
\hline
\end{tabular}
Levene's test. Though the ttests for these variables were significant (Table 5), it is recommended that inferences be drawn accordingly. 
Table 4. Platforms used most for gaming.

health. Even though a suf-

\begin{tabular}{lccccc}
\hline & Desktop & Laptop & Tablet & Mobile phone & TV console \\
\hline Younger adults & $4 \%$ & $16.2 \%$ & $1.2 \%$ & $40.7 \%$ & $37.9 \%$ \\
Older adults & $19.6 \%$ & $32.6 \%$ & $26.1 \%$ & $19.6 \%$ & $2.2 \%$ \\
\hline
\end{tabular}

ficiently large sample of 295 participants was recruited, the age distribution was very unequal. Thus, analyses were performed with a weighted

RQ5b: Considering their digital gaming frequency, how do younger and older adults' health measures (depression, positive and negative affect, physical health, and mental health) differ?

A series of simple linear regression analyses were performed with gaming frequency as a predictor of all health measures. Two statistically significant results emerged. Specifically, gaming frequency significantly predicts the overall PANAS, $F(1,209)=6.55, p=.011, r=.175$. For every one-unit increase in gaming frequency, people's scores on PANAS went down by .049 units. Gaming frequency explains 3\% of variance of PANAS. In addition, gaming frequency significantly predicts physical health, $\mathrm{F}(1,215)=7.35, \mathrm{p}=.007, \mathrm{r}=.182$. For every one-unit increase in gaming frequency, people's physical health decreases by 2.41 units. Gaming frequency explains $3.3 \%$ of variance of people's physical health.

When repeating these same analyses while including the continuous age variable as the second predictor, essentially controlling for age, results were significant for age, but none of the analyses showed significant results for gaming frequency, even when both variables were mean-centered.

RQ5c: Considering their most played game's genre, how do younger and older adults' health measures (depression, positive and negative effect, physical health, and mental health) differ? To answer this research question, ANCOVA was conducted with the unweighted sample. The genre of the most frequently played game was the covariate, with age groups as a fixed factor and the health measures as dependent variables.

Ten of the analyses were significant for age groups, with the "somatic and retarded activity" depression (CES-SA) sub-scale being the only one not to show a statistically significant result for age groups. Ten of the eleven analyses were not statistically significant for the game genre. However, the analysis showed that people's total score on PANAS differed by age group considering people's most played game's genre, $\mathrm{F}(1,273)=4.82, \mathrm{p}=.029, \eta^{2}=.017$. Specifically, the younger age group showed a higher PANA score $(M=2.59, S D=.42)$ than the older age group $(\mathrm{M}=2.30, \mathrm{SD}=.31)$. The comparison met Cohen's recommended power threshold of at least .80.

\section{Discussion}

The overall purpose of the study was to compare younger and older adults' gaming and sample. Results showed a number of differences between younger and older adults, both with regard to their gaming and their health.

Research question one asked about the types of games played by participants. With regard to genre, younger and older adults both enjoy puzzle games. This is consistent with recent findings (e.g., Blocker, Wright, \& Boot, 2014; Salmon et al., 2017). However, looking at nine possible areas of overlap (top 3 genres played, for top 3 games played), this was the only clear overlap. A small portion of older adults also play first-person shooter games, which are popular with younger adults. Card games, popular with older adults, were not popular with younger adults. These secondary preferences largely confirm the stereotype that younger adults are more action-oriented in their game choices (shooter games, sports games) than older adults who seem to choose more cognitive stimulation via their game choices (card games, simulation), and although both groups play puzzle games, there are still distinct differences in their gaming preferences. Practitioners seeking to engage people from the two age groups in a health gaming context should consider the game genre to increase patients' enjoyment (Diaz-Orueta et al., 2012) and adherence.

Research question two looked at the frequency with which younger and older adults play games. Results indicate that older adults play games significantly more frequently than younger adults. Comparing both daily gaming, and gaming within the past week, older adults were more likely to play more frequently than younger adults. Younger adults may spend more of their time on social media for entertainment purposes than do older adults. In that case, gaming would present only one of many uses of technology for entertainment purposes for younger adults. For older adults, despite common stereotypes, older adults may be quite interested in gaming for health and doing so frequently. As time passes, also, more people who are already gaming will enter the older age groups, further underscoring the importance of considering the role gaming - both casual and medical - can play for health.

Research question three examined differences in platform use. Overall, older adults were shown to be significantly more likely to use desktops and laptops for gaming, while younger adults were shown to be significantly more likely to use consoles. Both age groups use mobile de- 
Table 5. Game play influences.

\section{Younger sample}

Older sample

\begin{tabular}{|c|c|c|}
\hline Most played & $\begin{array}{l}\text { Friends already playing }(52.6 \% ; 3.8 \\
\text { times more likely, } \chi^{2}(1)=20.59, \\
p<.001) \\
\text { "Other" }(20.9 \%)\end{array}$ & $\begin{array}{l}\text { "Other" (23.3\%) } \\
\text { Friends already playing }(22.3 \%) \\
\text { Family member already playing (17.3\%) }\end{array}$ \\
\hline Second most & $\begin{array}{l}\text { Friends already playing }(47.5 \% ; 3.8 \\
\text { times more likely, } \chi^{2}(1)=22.83, \\
p<.001) \\
\text { "Other" }(16.9 \%)\end{array}$ & $\begin{array}{l}\text { Family member already playing }(26.2 \% ; 2.88 \\
\left.\text { times more likely, } \chi^{2}(1)=6.34, p<.05\right) \\
\text { Friends already playing }(18.3 \%) \\
\text { "Other" }(18.2 \%)\end{array}$ \\
\hline Third most & $\begin{array}{l}\text { Friends already playing }(39.6 \% ; 2.8 \\
\text { times more likely, } \chi^{2}(1)=12.77, \\
p<.001) \\
\text { "Other" }(16.2 \%)\end{array}$ & $\begin{array}{l}\text { Friends already playing }(25.4 \%) \\
\text { Family member already playing }(17.2 \%) \\
\text { Discussion/non-advertising presentation seen } \\
\text { on TV }(10.5 \%)\end{array}$ \\
\hline
\end{tabular}

Note: Chi-square results show how much more likely one group was than the other to identify this source as an influence to begin playing. Only significant results are reported.

vices, with younger adults being more likely to use them "most," and older adults being more likely to use them "regularly" along with other platforms. Game developers should take these preferences into account when developing health games for particular audiences, especially as effect sizes were moderate to strong.

Research question four examined the factors that influenced younger and older adults to begin gaming. Overall, friends who were already playing the game were a strong influence on both age groups, supporting Eklund's (2015) notion that offline relationships are affecting digital gaming. This assertion is further strengthened by the result that family was a very strong influence on older adults' decision to begin playing a specific game. Clearly, offline relationships are affecting behavior in the digital realm and health practitioners may be able to capitalize on this, such as via group gaming therapy sessions.

Finally, research question five, broken into three parts, assessed participants' health. Results showed that younger adults experienced significantly more depression, more negative affect, and better physical health than older adults. Older adults, in return, experienced better mental health than younger adults (question 5a). Effect sizes where small to moderate. This result is particularly interesting in the context of previous research that showed that older adults have greater concern about the negative health effects of gaming (Nap et al., 2009).
Table 6. Comparing younger versus older adults on five health measures.

\begin{tabular}{|c|c|c|c|c|c|c|c|c|}
\hline & $\mathbf{t}$ & df & $\mathbf{p}$ & & $\mathbf{N}$ & $M$ & SD & d \\
\hline \multirow[t]{2}{*}{ CES_total } & 3.28 & 214 & $<.001^{* * *}$ & $Y$ & 114 & 2.17 & .39 & .442 \\
\hline & & & & $\mathrm{O}$ & 102 & 2.01 & .33 & \\
\hline \multirow[t]{2}{*}{ CES_DA } & 2.92 & 214 & $.004 * * *$ & $Y$ & 114 & 1.75 & .72 & .405 \\
\hline & & & & $\mathrm{O}$ & 102 & 1.47 & .66 & \\
\hline \multirow[t]{2}{*}{ CES_PA } & -2.87 & 215 & $.004 * * *$ & Y & 115 & 3.16 & .66 & .387 \\
\hline & & & & $\mathrm{O}$ & 102 & 3.44 & .78 & \\
\hline \multirow[t]{2}{*}{ CES_SA } & 2.21 & 215 & $.028^{* * *}$ & Y & 115 & 1.89 & .56 & .318 \\
\hline & & & & $\mathrm{O}$ & 102 & 1.70 & .63 & \\
\hline \multirow[t]{2}{*}{ CES_IA^ } & 4.11 & 212.02 & $<.001^{* * *}$ & Y & 115 & 1.62 & .71 & .574 \\
\hline & & & & $\mathrm{O}$ & 102 & 1.25 & .57 & \\
\hline \multirow[t]{2}{*}{ CES_OA } & 3.69 & 215 & $<.001^{* * *}$ & Y & 115 & 1.78 & .57 & .503 \\
\hline & & & & $\mathrm{O}$ & 102 & 1.48 & .62 & \\
\hline \multirow[t]{2}{*}{ PANA_total^ } & 5.48 & 203.65 & $<.001^{* * *}$ & Y & 113 & 2.59 & .41 & .779 \\
\hline & & & & $\mathrm{O}$ & 98 & 2.31 & .30 & \\
\hline \multirow[t]{2}{*}{ PANA_PA } & .535 & 210 & .593 & Y & 114 & 3.44 & .74 & .081 \\
\hline & & & & $\mathrm{O}$ & 98 & 3.38 & .74 & \\
\hline \multirow[t]{2}{*}{ PANA_NA } & 5.69 & 214 & $<.001 * * *$ & Y & 114 & 2.08 & .72 & .776 \\
\hline & & & & $\mathrm{O}$ & 102 & 1.54 & .67 & \\
\hline \multirow[t]{2}{*}{$\mathrm{PCS}^{\wedge}$} & 3.40 & 136.05 & $<.001^{* * *}$ & Y & 115 & 81.22 & 10.63 & .454 \\
\hline & & & & $\mathrm{O}$ & 102 & 72.80 & 23.92 & \\
\hline \multirow[t]{2}{*}{ MCS } & -4.24 & 215 & $<.001^{* * *}$ & $Y$ & 115 & 64.26 & 21.07 & .578 \\
\hline & & & & $\mathrm{O}$ & 102 & 76.05 & 19.69 & \\
\hline
\end{tabular}

***Significant at $p<=001$. ^These variables had non-significant Levene's tests. CES_total - CES Depression scale; CES_DA - CES Depressed Affect sub-scale; CES_PA - CES Positive Affect sub-scale; CES_SA - CES Somatic \& Retarded Activity sub-scale; CES_IA - CES Interpersonal sub-scale; CES_OA - CES Other Items sub-scale; PANA_total - Overall PANA scale; PANA_PA - PANA Positive Affect sub-scale; PANA_NA - PANA Negative Affect sub-scale; PCS - Physical Health scale; MCS - Mental health scale; $\mathrm{O}$ - older participants; $\bar{Y}$ - younger participants.
Re-examining health measures in light of digital gaming frequency across age produced two significant results. Specifically, gaming frequency explained $3 \%$ of variance of the overall positive effect/negative affect schedule (PANAS), as well as $3.3 \%$ of variance in physical health. In both cases, as gaming frequency increased, scores on the other variable decreased, certainly a socially negative result for physical health. These results confirm stereotypes, as well as prior research that showed that screen time associated with gaming can have negative physical effects (e.g., Norman et al., 2017). In this par- 
ticular case, the result is likely due to the older group's higher frequency of gaming compared to the younger group's, combined with the natural phenomenon of older people generally experiencing lower health. This age effect is supported by the fact that gaming frequency was not a significant predictor when it was entered with age together in multiple regression. When gaming is used specifically to address physical rehabilitation, results are likely to be different.

Looking at the game genre and the health measures across age produced only one significant result, namely that younger adults had a higher overall PANAS score than older adults when taking the most played game's genre into account. For both groups, puzzle games were the most popular genre for the most played game. As such, this result provides some support for the interpretation that puzzle games provide an opportunity for adults of all ages to experience a positive life effect from gaming, but especially for younger adults.

\section{Conclusion}

The results of this study presented a number of significant differences and similarities between young and older adults' gaming and health. For example, older adults appear to game more frequently than younger adults (RQ2). Gaming frequency and genre (RQ5) also showed an effect on both physical health and scores on the overall PANAS. While variance explained by gaming frequency was comparatively low in both cases, the result implicitly cautions that gaming should be enjoyed in moderation.

The study also found several non-significant results. In this case, non-significant results are interesting, especially as they were found with the un-weighted sample with Levene's test showing equal variances despite distinct differences in group size. One would expect the game genre to have a broader effect, as shooting games are certainly more likely to be the focus of violence than puzzles. Finding few significant differences in health measures across age groups when entering gaming variables (RQ5b\&c) leads us to believe that the question deserves more attention. After all, health differences were found without these moderating variables (RQ5a). The results may indicate that younger and older adults' health may be affected similarly (or, at least, not differently) by gaming. If genre and platform preferences are taken into account, practitioners may be able to expect similar effects of gaming on health across the adult lifespan, especially as current gameplaying younger and middle-aged adults grow older and enter the "older adults" age group.
Additional research is needed to confirm this interpretation. However, this study helps future researchers by identifying where to look. Simply using a larger sample of older adults is not likely to produce significant results because, for almost all comparisons, power analysis met Cohen's generally accepted threshold. Possibly, recruiting a more diverse sample overall (including educational and racial/ethnic backgrounds) may lead to different results, as may recruiting participants with ages ranging across the entire adult lifespan, not just at the two endpoints. We also encourage other researchers to divide their participants not just by age, but also by gender. We found a significant difference among younger adults with regard to frequency of game play with men playing more often than did women. No such difference was found with the older adult sample. Possibly, the difference in play frequency between genders disappears as people grow older, as happens with depression, and it was this genderrelated aspect that led to our non-significant results rather than age.

Finally, our results should be of interest to those developing campaigns about or for games. Identifying a platform (mobile; RQ3) and a genre of games (puzzle; RQ1) that appeal to adults at both ends of the age continuum indicates that this platform and genre generate broad interest. Campaigns can be designed accordingly, including health, marketing, political, and pro-social campaigns. Results also indicated that a two-step flow (Katz \& Lazarsfeld, 1955) or diffusion (Rogers, 2003) model is likely successful in marketing games to adults of both ages, though with slightly different foci. Both age groups identified interpersonal channels (friends, family; RQ4) as primary influences on their decision to begin playing a specific game. Such interpersonal channels may also be useful in health or therapy settings to increase motivation and gaming adherence in reluctant patients across the adult life span.

The study at hand did not ask whether the family member influencing the older adult was a young adult or someone in another age group. If it is a young adult family member, then influencing young adults could reach two age groups: other young adults (friends), as well as older adults (family members). Targeted advertising and marketing would be recommended in that case, likely following a viral marketing-type approach. There is the potential for expanding the older-adult casual gaming market to a larger degree than has been done so far. Allaire et al. (2013) showed that older adults who game actually tend to be healthier than older adults who do not game, so there are pro-social reasons to tackle this issue. 


\section{Acknowledgements}

The authors declare that there is no conflict of interest in this research. IRB protocol/approval number: 2017.20655.

\section{References}

"About AARP." (n.d.) Retrieved from https://www.aarp. org/about-aarp/?intcmp=AE-HP-FTR-ABOUT

Allaire, J. C., McLaughlin, A. C., Trujillo, A., Whitlock, L. A., LaPorte, L., \& Gandy, M. (2013). Successful aging through digital games: Socioemotional differences between older adult gamers and non-gamers. Computers in Human Behavior, 29, 1302-1306.

Anderson, C. A., Shibuya, A., Ihori, N., Swing, E. L., Bushman, B. J., Sakamoto, A., Rothstein, H. R., \& Saleem, M. (2010). Violent video game effects on aggression, empathy, and prosocial behavior in eastern and western countries: A meta-analytic review. Psychhological Bulletin, 136(2), 151-173.

Bethlehem, J. (2009). Applied survey methods - A statistical perspective. Hoboken: Wiley.

Bisson, E., Contant, B., Sveistrup, H., \& Lajoie, Y. (2007). Functional balance and dual-task

reaction times in older adults are improved by virtual reality and bio-feedback training.

CyberPsychology \& Behavior, 10, 16-23.

Bleakley, C. M., Charles, D., Porter-Armstrong, A., McNeill, M. D., McDonough, S. M., \& McCormack, B. (2015). Gaming for health: A systematic review of the physical and cognitive effects of interactive computer games in older adults. Journal of Applied Gerontology, 34(3), NP166-NP189.

Blocker, K., Wright, T., \& Boot, W. (2014). Gaming preferences of aging generations. Gerontechnology, 12(3), 174-184.

Brown, A. (2017, September 11). Younger men play video games, but so do a diverse group of other Americans. Pew Research Center. Retrieved from http://www.pewresearch.org/fact-tank/2017/09/11/ younger-men-play-video-games-but-so-do-a-diverse-group-of-other-americans/

Chua, P. H., Jung, Y. B., Lwin, M. O., \& Theng, Y. L. (2013). Let's play together: Effects of video-game play on intergenerational perceptions among youth and elderly participants. Computers in Human Behavior, 29(6), 2303-2311.

Costa, L., \& Veloso, A. (2016). Being (grand) players: Review of digital games and their potential to enhance intergenerational interactions. Journal of Intergenerational Relationships, 14(1), 43-59.

de Bruin, E. D., Schoene, D., Pichierri, G., \& Smith, S. T. (2010). Use of virtual reality technique for the training of motor control in the elderly. Some theoretical considerations. Zeitschrift für Gerontologie und Geriatrie, 43, 229-234.

De Schutter, B. (2011). Never too old to play: The appeal of digital games to an older audience. Games and Culture, 6(2), 155-170.

Duggan, M. (2015, December 15). Which Americans play video games and who identifies as a "gamer." Pew Research Center. Retrieved from http://www. pewinternet.org/2015/12/15/who-plays-videogames-and-identifies-as-a-gamer/

Eklund, L. (2015). Bridging the online/offline divide: The example of digital gaming. Computers in Human Behavior, 53, 527-535.

Fent, D., Little, C., Garver, K., Murray, C., \& Todd, J. (2015). Effects of active video games (Wii Fit TM) on senior adult balance, fitness and mood. Gerontologist, 52, 585-585

Ferguson, C. J., Coulson, M., \& Barnett, J. (2011). A meta-analysis of pathological gaming prevalence and comorbidity with mental health, academic and social problems. Journal of Psychiatric Research, 45(12), 1573-1578.

Griffiths, M. D., Davies, M. N., \& Chappell, D. (2004). Online computer gaming: a comparison of adolescent and adult gamers. Journal of adolescence, 27(1), 87-96.

Jones, C. J., Scholes, L., Johnson, D., Katsikitis, M., \& Carras, M. C. (2014). Gaming well: links between videogames and flourishing mental health. Frontiers in Psychology, 5(260), 1-8.

Katz, E., \& Lazarsfeld, P. (1955). Personal influence: The part played by people in the flow of mass communications. New York: Free Press.

LaRose, R., Lin, C. A., \& Eastin, M. S. (2003). Unregulated Internet usage: Addiction, habit, or deficient self-regulation? Media Psychology, 5, 225-253.

Lenhart, A., Jones, S., \& MacGill, A. (2008, December 8). Adults and video games. Pew Research Center, Retrieved from http://www.pewinternet. org/2008/12/07/adults-and-video-games/.

MacGill, A. (2007). Is video gaming becoming the next family bonding activity? Pew Research Center. Retrieved from http://www.pewinternet. org/2007/11/19/is-video-gaming-becoming-thenext-family-bonding-activity/.

Nap, H. H., IJsselsteijn, W. A., \& De Kort, Y. A. (2009). Age Differences in Associations with Digital Gaming. In DiGRA Conference.

Norman, G. J., Carlson, J. A., Patrick, K., Kolodziejczyk, J. K., Godino, J. G., Huang, J., \& Thyfault, J. (2017). Sedentary behavior and cardiometabolic health associations in obese 11-13-year olds. Childhood Obesity, 13(5), 425-432.

Peng, T., \& Zhu, J. J. H. (2011). Sophistication of internet usage (SIU) and its attitudinal antecedents: An empirical study in Hong Kong. Computers in Human Behavior, 27, 421-431.

Primack, B. A., Carroll, M. V., McNamara, M., Klem, M. L., King, B., Rich, M., \& Nayak, S. (2012). Role of video games in improving health-related outcomes: a systematic review. American journal of preventive medicine, 42(6), 630-638.

Quandt, T., Grueninger, H., \& Wimmer, J. (2009). The gray haired gaming generation: Findings from an explorative interview study on older computer gamers. Games and Culture, 4(1), 27-46.

Radloff, L. S. (1977). The CES-D scale: A self-report depression scale for research in the general population. Applied Psychological Measurement, 1(3), 385-401.

Rogers, E. M. (2003). Diffusion of innovations. New York: Free Press.

Salmon, J. P., Dolan, S. M., Drake, R. S., Wilson, G. C., Klein, R.M., \& Eskes, G. A. (2017). A survey of video game preferences in adults: Building better games for older adults. Entertainment Computing, 21, 45-64. 


\section{Examining digital gaming habits and health measures}

Soler-Lanagran, A., \& Castaneda-Vazquez, C. (2017). Sedentary lifestyle and health risks in children. A systematic review. Journal of Sport and Health Research, 9(2), 187-198.

Ware, J. E., \& Gandek, B. (1998). Overview of the SF-36 health survey and the International Quality Of Life
Assessment (IQOLA) project. Journal of Clinical Epidemiology, 51(11), 903-912.

Watson, D., Clark, L. A., \& Tellegen, A. (1988). Development and validation of brief measures of positive and negative affect: The PANAS scales. Journal of Personality and Social Psychology, 54(6), 1063-1070. 